\title{
MATIZ RELIGIOSO DE DOS OBRAS ESCULTORICAS DEL PARQUE DE ELCHE
}

\author{
RAFAEL RAMOS FERNÁNDEZ
}

Un aspecto especialmente significativo de los hallazgos escultóricos del Parque de Elche (1) es el correspondiente a su vinculación a la religiosidad íbera puesto que en ellos está presente la pareja divina, la Gran Diosa y su consorte representado físicamente por un toro, según la idea de los cultos de fertilidad.

La Diosa forma parte de un grupo asociado a una esfinge. Se trata de una obra en piedra caliza esculpida en bulto redondo si bien una de sus caras apenas fue desbastada, indicio de su posición adosada a un muro. Consta de una esfinge cuya cabeza no ha sido hallada aunque su lugar queda bien indicado por las trenzas de su cabellera que con un marcado resalte descienden a lo largo de su cuello. Se muestra en posición echada, con las patas delanteras y traseras plegadas; sus garras tienen dedos humanoides de largas falanges y articulaciones marcadas por angulaciones acusadas; y en su punto de unión con los brazos aparecen resaltes que representan pulseras. Su cola se extiende entre las ancas ocupando el espacio libre que queda bajo su vientre. Su ala arranca sobre el codo de la pata delantera a partir de un filete semilunar y se compone de una banda lisa superior y una zona baja con anchos plumones estilizados. Sobre sus garras delanteras y en pie se encuentra una figura femenina con los brazos cruzados y la cabeza erguida, con peinado egiptizante, con alas plegadas sobre la parte delantera del cuerpo y que presenta en su pecho la flor de loto. Representa pues a la Gran Diosa alada, a aquella que más tarde caracterizará a las cerámicas ibéricas pintadas de Elche. En la grupa de la esfinge y por la parte interior del ala existe otro personaje, hoy acéfalo, que se sujeta con las manos al cuello del animal y puede simbolizar el alma del difunto que es así transportada al más allá por esta especie alada psicopompa a quien conduce y guía la Gran Diosa.

Sus dimensiones son: $120 \times 64 \times 32 \mathrm{cms}$.

(1) Ramos, R. (1985): “Excavaciones arqueológicas en el Parque de Elche». POBLAD. II-7. Elche, págs. 30-33; 1986. "La investigación arqueológica». Cien años de historia de Elche. CAAM, Alicante, págs. 79-85; e/p. "Demarcación ibérica en el Parque de Elche». XVIII C.N.A. Islas Canarias; 1986. "Parque de Elche". Arqueología en Alicante. I.E. "J. Gil-Albert". Alicante, págs. 130-133; e/p. "La esfinge de Elche». HELIKE, II, U.N.E.D.; Ramos, A.-Ramos, R. (1976): "Excavaciones al Este del Parque Infantil de Tráfico en Elche». N. Arq. H., Arq. ${ }^{a}$ IV. Madrid. 
El Toro es una obra de piedra caliza, en bulto redondo, de la que se conserva su parte superior, vaciada interiormente, y las dos patas delanteras esculpidas en altorrelieve. El resto de la pieza, no localizado, suponemos que constituyó una caja cineraria. Presenta la boca entreabierta mostrando unos molares asemejables a los humanos, resaltados por triángulos inscritos en su zona de arranque. Su cabeza y cuello están cubiertos por un fuerte estriado convencional que idealiza la pieza, enmarca unos ojos almendrados con largas pestañas superiores y limita un espacio frontal donde se marca un flequillo de testuz que parece recordar el de los pequeños toros anatolios; tiene orificios de inserción y de sujección para orejas y cuernos, y puntos de fijación para el hocico, que debieron ser sobrepuestos. Su lomo presenta unos omoplatos muy marcados que asemejan aletas y favorecen la sensación de irrealidad de la obra.

Sus dimensiones son: $90 \times 67 \times 43 \mathrm{cms}$.

Estas obras escultóricas tienen un evidente caracter orientalizante aunque parecen haber sido motivadas a través de lo griego arcaico, posibilidad que podría explicarse como el reflejo de unas ideologías sirio-egipcias plasmadas por íberos con técnicas de las escuelas helenas, puesto que en estas obras existen peculiaridades indicadoras de su producción íbera. Pues si bien la piedra en que fueron esculpidas procede de las canteras locales, esto sólo es indicio de que se realizaron en un taller local pero no evidencia de que el artista fuera indígena; sin embargo, tanto estilística como técnicamente, contienen datos que manifiestan su autoctonía, porque la esfinge estuvo realizada para situarse adosada a un muro, mientras que las griegas fueron exentas, y porque su cola se introduce entre las ancas a su vez que en las griegas se dobla sobre sí misma y se coloca sobre el muslo (2). No obstante esta pieza es una libre interpretación íbera de modelos griegos como puede apreciarse en el arranque del ala y en su inclinación; por otra parte, la composición de esta obra expresa que su autor conocía el significado griego de la esfinge de época arcaica: protectora de los difuntos a quienes podía transportar el alma a la otra vida. Se trata pues de una iconografía sirio-fenicia con asociaciones egiptizantes matizada por lo griego arcaico que puede implicar además la presencia en Iberia de elementos chipriotas y egipcios que paulatinamente quedaron sojuzgados por las aportaciones helenas.

La figura femenina alada que conduce a la esfinge desde su posición en las garras delanteras representa a la Gran Diosa, la «divinidad única a quien venera el mundo entero bajo múltiples formas, variados ritos y los más diversos nombres (3)». Es la Diosa de la vida, la soberana del mundo por la fuerza omnipotente del amor, el poder nutricio de la tierra, soberana de la vida y de la muerte, la reina del cielo y señora de las estrellas, es la luna, la reina del mundo de los muertos, la diosa del mar, la madre de la naturaleza, la dueña de todos los elementos, el vientre en-

(2) Chapa, T. (1980): "La escultura zoomorfa ibérica en piedra". Univ. Compl. de Madrid. Tesis Doctoral, tomo II, págs. 943 y 945.

(3) Apuleyo: "Metamorfosis», XI. 

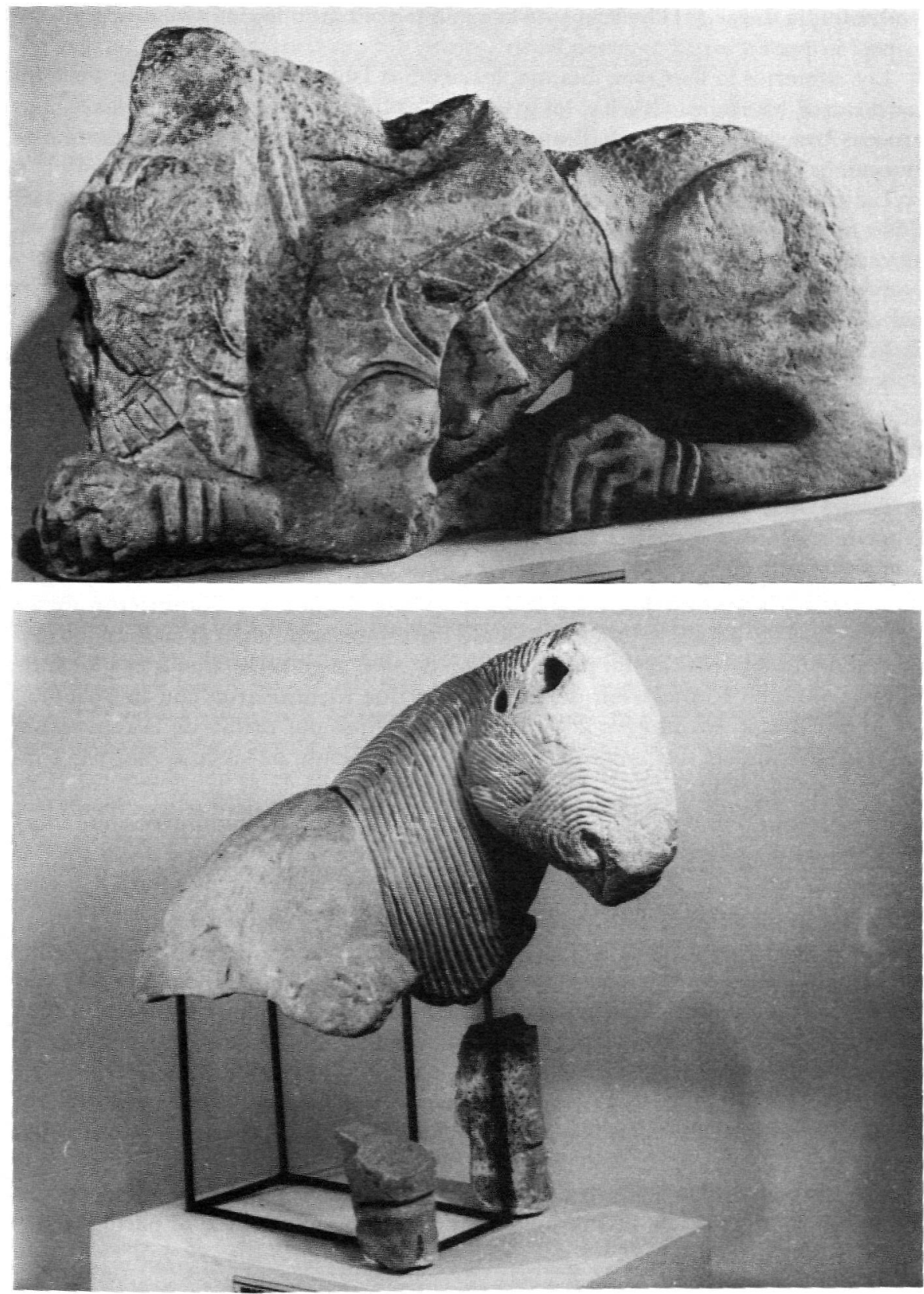

LAM. I.-1. Diosa alada. Detalle frontal de la Esfinge de Elche. 2. Toro del Parque de Elche. 
gendrador, la diosa de la belleza y de la fertilidad. El mundo está amparado y regido por su poder.

Los sumerios la llamaron Inanna, los acadios Ishtar, los egipcios Isis, los fenicios Astarté, los frigios Cibeles, los griegos Afrodita, Artemis Efesia los foceos, los etruscos Uni, los cartagineses Tanit, los romanos Juno, y de la que por ahora desconocemos su advocación íbera.

La iconografía de esta obra tiene paralelos en el sarcófago y las terracotas de la Necrópolis de Santa Mónica, en las terracotas de la Cueva des Cuieram y en las cerámicas pintadas de La Alcudia de Elche.

El compañero de la Gran Diosa es siempre un toro. Y también aquí, en el Parque de Elche, formando parte del alineamiento pétreo descubierto, apareció asociado a ella.

El toro es la materialización del espíritu de los dioses de la vida, de la muerte y de la resurrección. De Dumuzi, Tammuz, Osiris, Eshmún/Baal, Adonis, Tinia o Melkart/Resef, que debe morir para que pueda producirse el misterio de la resurrección anual, el ciclo vegetativo, el misterio de la vida. El toro muere con carácter de sacrificio como renovación, para que se produzca la vuelta de la vegetación y, por asociación a esta idea, la vuelta de todas las formas de vida.

Pero ¿por qué un toro? Posiblemente porque durante los milenios IV y III a. J.C., durante la Era de Tauro, período en el que surgieron y adquirieron forma las religiones del Próximo Oriente, cuando los hombres miraban al cielo en los momentos de los equinoccios de primavera veían en él algo semejante a la silueta de un toro, veían la constelación de Tauro. Toro que identificaron con la divinidad por lo que dieron esa imagen al espíritu del dios que por medio de la renovación anual (4) permitía el surgimiento cíclico de la vegetación, de las cosechas, y la continuidad de la vida.

El toro es la representación materializada del alma de las divinidades que mueren y resucitan en íntima relación con la muerte y resurrección anual de los vegetales sobre la tierra. Es el dios que muere pero no muere porque despierta a la vida después de la muerte. Muere siempre sacrificado y resurge porque muere con objeto de renacer y así representa la renovación, el Gran Círculo, el eterno retorno.

Esta divinidad complementa y sirve a la diosa como amante, amigo y víctima. Sus ciclos responden a la secuencia de la vida física: nacimiento y muerte, día y noche o verano e invierno. Para que pueda producirse el renacimiento es imprescindible la destrucción porque para que la vida siga y se renueve debe necesariamente destruirse ya que exige renovación a través de la muerte para fundir la extinción de lo viejo con el nacimiento de la vida nueva ya que toda creación exige sacrificio.

Con este motivo las gentes que practicaron su culto celebraron festividades anuales durante el equinoccio de primavera en las cuales la comunidad, al participar del rito de muerte y renacimiento del dios, también se renovaba. 
Así la religiosidad se cifraba en el ciclo vital regido por los astros y la renovación vegetal, y a su vez el aspecto funerario y ritual participaba de los mismos principios.

El Año Nuevo rememoraba el inicio de la vida, la vuelta del dios y la promesa del retorno de las cosechas. Existieron escenarios rituales en los que se representaba el final del Año Viejo y el comienzo del Nuevo con el deseo de abolir el tiempo ya transcurrido e instaurar el que había de venir, lo que se celebraba con las ya citadas fiestas periódicas que cierran un ciclo temporal y abren otro nuevo que supone una regeneración. Estos ritos, dedicados a desterrar una etapa pasada, se realizaban con purificaciones, con la quema de las efigies del Año Viejo con la intención de suprimirlo. "Apagar los fuegos equivale a instaurar las tinieblas, la noche cósmica en la que todas las formas pierden sus contornos y se confunden. En el plano cosmológico tinieblas y caos son una misma cosa, como volver a encender el fuego simboliza la creación, la restauración de las formas y de los límites (5)». En ese momento que transcurre entre los dos "tiempos" es posible la comunicación entre los vivos y los muertos, entre las formas definidas y lo que no tiene forma.

La ausencia de antropomorfismo en la representación del dios macho parece responder, al igual que ocurrió en Chipre hasta época arcaica, a la creencia de que las fuerzas masculinas de la fecundidad no se encarnaban bajo forma humana.

En el área chipriota, ya en la Edad del Broncé, las maquetas de Vounous o de Kotchati muestran los cultos, ritos o ceremonias debidos al toro; asimismo, en vasos figurados ofrecen toros junto a figuras femeninas asociadas a sus símbolos o animales atributo: aves y serpientes. Son imágenes que se mantienen hasta el I milenio a. J.C. en los santuarios de los dioses masculinos, que ya en el Chipriota Reciente se caracterizan por la presencia de altares con cuernos de consagración de tipo relacionable con el cretense. El carácter religioso del toro parece residir fundamentalmente en sus cuernos, elemento de gran importancia en el culto y la simbología que posiblemente llegó a Chipre procedente de Anatolia.

Estos cultos chipriotas se desarrollaron con (6) recipientes que contenían el agua de los ritos de lustración, ritos que prosiguieron durante el I milenio a. J.C. y que pueden ser paralelizables a los desarrollados por los íberos, detectables tanto en algunas de sus necrópolis como en las llamadas cuevas santuario (7).

El culto dado a las fuerzas de la fecundidad parece tener un matiz esencialmente funerario pues tal vez la invocación (8) a una divinidad de la fertilidad garantizara la supervivencia o la regeneración del muerto. Así pues, las ceremonias religiosas relacionables con el toro responderían a un culto de las fuerzas de la fecun-

(5) Eliade, M. (1981): "Tratado de Historia de las religiones. Morfología y dinámica de lo sagradow. Madrid, pág. 440.

(6) Caubet, A. (1979): "La religion a Chypre dans l'Antiquite». Maison de l'orient, H. S., 2, Lyon, pág. 13.

(7) Blazquez, J. M. (1983): “Religiones prerromanas». Primitivas religiones ibéricas, II. Madrid, pág. 112; Llobegat, E. (1981): "Toros y agua en los cultos funerarios ibéricos». SAGUNTUM, 16, Valencia, pág. 162.

(8) Karageorghis, J. (1977): "La Grande Déese de Chypre et son culte", C.M.O.M.A., 5; S. Arq., 4, Lyon, págs. 43 y 44 . 
didad asociado a la vida y la muerte. Por lo que esta expresión de determinadas creencias religiosas se materializa con la representación zoomorfa de los principios divinos en relación con las fuerzas fecundantes de la naturaleza. La divinidad masculina no toma forma humana.

En el santuario de la Gran Diosa anatolia de Çatal-Huyuk las representaciones de aquella están asociadas a bucráneos e incluso existen escenas en las que la propia diosa da a luz un toro y otras donde ella se une al toro en un hieros-gamos. Es la diosa cuyo consorte es su amante y su hijo.

Asimismo, también en la Creta minoica la diosa estaba asociada a los toros, a bucráneos y a los cuernos del toro.

Las divinidades femeninas (9), bajo sus diversos nombres, eran las diosas de la fecundidad, responsables del mantenimiento de la vida humana, animal y vegetal. Eran a la vez madres y esposas, celebraban sus bodas con sus hijos que a su vez eran sus amantes. El matrimonio sagrado se consumaba y se festejaba periódicamente con el fin de asegurar la renovación de las fuerzas de la vida. Pero, dentro del ciclo anual, el consorte, el dios, desaparecía o moría en determinado momento y la diosa lloraba aquella ausencia que ocasionaba la pérdida de las fuerzas de la naturaleza. Durante tal etapa la diosa lo buscaba sin descanso descendiendo incluso a los dominios infernales. Mientras tanto la vida sobre la tierra se marchitaba. Pero cuando lo encontraba, cuando volvía a vivir sobre la tierra, en la etapa nueva, en el año nuevo, en los inicios de la primavera, volvía la prosperidad.

La asimilación iconográfica (10) en el área ibérica recoge elementos de diverso origen y los reelabora integrándolos a su modo de forma que tanto las imágenes como las ideas que se desprenden de piezas importadas se aglutinan motivando que obras de zonas sirio-fenicias, egipcias, chipriotas o griegas, transmitidas por los fenicios o por los griego-anatolios, se difundieran por el Mediterráneo. Si bien suponemos que fueran los púnicos quienes pudieron haberlas hecho llegar a estas tierras del occidente.

Por otra parte, es presumible que los cultos egipcios matizaran la religión griega y que la técnica artesanal y artística griega fuera la materializadora de la expresión plástica sincretizadora de la idea de la divinidad femenina; y a su vez se podría indicar que Chipre fue el punto de encuentro de hombres y creencias que pudo fusionar las ideas y llegar a elaborar una iconografía de la diosa a partir de la unión de elementos y símbolos egipcios, sirios y griego-anatolios.

Desde épocas prehelénicas son muchas las piezas encontradas en territorios griegos relacionadas con el mundo egipcio, piezas que tienen contenido religioso y que pueden informar de la transmisión de creencias que debió producirse de Egipto a Grecia.

Ciertos centros comerciales griegos se convirtieron en receptores y difusores de cultos recibidos de Siria y de Egipto, al tiempo que los mercaderes y los mercena-

(9) Karageorghis, J. (1977): Pág. 79.

(10) Olmos, R. (1986): "Quelques observations sur l'assimilation de l'icinographie grecque dans le monde iberique (II)m. Iconographie Classique et Identités Règionales. Bull. Corresp. Hellènique, S. XIV, Paris, págs. 155-166. 
rios eran los transmisores directos. Así es especialmente importante en el tema que nos ocupa el valorar la realidad de los hallazgos egipcios que se han efectuado en Jonia y en Lidia.

En función de los materiales y de su procedencia, tras los estudios realizados (11), parece evidente el hecho de la introducción real de determinados factores de la religiosidad egipcia en la cultura griega: Los cultos de Isis y Osiris, después Serapis, dioses de la fertilidad, rectores del ciclo vital, se integraron en la corriente sincrética que afectaba a Grecia y dieron lugar a los ritos mistéricos helenos. Desde el siglo VIII a. J.C., tras una etapa en que lo egipcio sólo afectaba a aspectos mágicos y a creencias populares, hasta fines dle siglo $\mathrm{V}$ a. J.C. los cultos y ritos importados de Egipto se integran en ciertas comunidades griegas. Asimismo, es relativamente frecuente el hallazgo de pequeños objetos egipcios o egiptizantes en las necrópolis íberas, piezas que también aportarían su impacto iconográfico a este mundo.

Por todo ello, la iconografía que nos ofrece esta imagen de la Gran Diosa íbera parece proceder de un sincretismo orientalizante en el que la isla de Chipre debió jugar un papel importante debido a su situación que implica la encrucijada de todos los caminos que surcan esa zona del Mediterráneo.

Chipre sirvió de intermediario (12) en la transición al mundo griego del motivo iconográfico oriental que suponían las imágenes de comensales tumbados, representaciones que surgieron en Asiria y que el mundo chipriota introdujo en Jonia, de donde debió pasar a Grecia y a la Magna Grecia; y también debió jugar un papel importante en la transmisión al mundo griego de la representación egipcia del alma del muerto por un ave con cabeza humana, guardando el sentido funerario del alma-ave egipcia. Asimismo, las representaciones de divinidades que sostienen una maza en su diestra y se presentan dominando a un león son frecuentes en los santuarios chipriotas de épocas arcaica y clásica. La procedencia oriental de estos tipos iconográficos parece evidente pues la actitud de un personaje blandiendo una maza debe derivarse de los dioses sirios de la tempestad y la de aquellos que sostienen por las patas traseras a un pequeño león parece venir de los héroes asirios y del pseudo-Gilgamesh como testimonios más recientes. Esas dos actitudes, brazo levantado y león dominado, posiblemente se fusionaron en territorio fenicio y posiblemente también fueran los fenicios quienes llevaron a Chipre el culto de Melkart. Consiguientemente pudo ser algún punto de Chipre el lugar donde se produjo la asimilación entre el Melkart fenicio, jefe de los animales, y el Herakles griego, vencedor del león de Nemea; al igual que también allí de la Astarté fenicia surgió la Afrodita griega.

Con respecto a la iconografía de esta representación de la diosa hallada en Elche intentamos precisar la existencia de dos focos que se relacionarán con lo que por una parte podría llamarse origen remoto de la misma para así diferenciarlo, por otra, de su difusión occidental.

(11) Ovejero, J. R. (1984): “Testimonios arqueológicos de la difusión de los cultos egipcios en el mundo griego oriental antes del siglo II a. J.C.». Bol. M.A.N., II, 1, Madrid, págs. 85-102.

(12) Caubet, A. (1979): Págs. 18, 33 y 34. 
La plasmación plástica de esta idea religiosa, este sincretismo de la divinidad femenina, sería paralelizable con lo ocurrido en los talleres broncistas chipriotas en donde los artesanos locales utilizaron los conocimientos técnicos de los fundidores sirio-palestinos y los combinaron con la conciencia egea de la dignidad y del esplendor formal del cuerpo humano. Posiblemente así la Gran Diosa oriental transformó su imagen con el transcurso del tiempo debido al contacto con la cultura occidental aportada por los griegos y los cretenses, llegando a ofrecer el aspecto de una divinidad imponente, ricamente vestida, que se había espiritualizado y alcanzaba paulatinamente una gran humanidad.

La diosa desnuda oriental tomó probablemente de Egipto su peinado y del área griega su ropaje.

Durante el siglo VI a. J.C. fue especialmente significativa en Chipre la presencia egipcia en todos los aspectos, de ello es exponente la temática de los vasos pintados de Amatonte (13), y la estatuaria alcanzó un extraordinario desarrollo tomando sus modelos de la iconografía sirio-anatolia y egipcia (14), a los que se sumaron a partir del 550 a. J.C. los modelos jonios. Tal fusión iconográfica dio lugar no sólo a un tipo distinto a lo anterior en cuanto a la representación de la Gran Diosa sino también a la plasmación de auténticas preocupaciones religiosas. La Gran Diosa así había cambiado de aspecto: Bajo el influjo de tipos cretenses se transformó en una figura vestida y de Siria y Egipto mantuvo sus alas. Así, de sus orígenes orientales conservó su naturaleza de diosa de la fecundidad, protectora de la vida, y de sus raíces griegas presentó su gran dignidad y su aspecto humano.

En Chipre se amalgamaba todo el Oriente. La iconografía resultante de la fusión de modelos egipcios y sirio-palestinos pasó a ejecutarse por maestros griegos y el resultado transportado por los fenicios, como objeto y como idea, a Cartago desde donde probablemente se adoptó en Iberia; si bien Sicilia, a su vez, también fusionó lo helénico y lo púnico, reafirmando una misma realidad que se extendió hacia el Occidente Mediterráneo.

Por ello esta imagen de la diosa, que tal vez se produjo en el área citada, pudo desplazarse durante la segunda mitad del siglo VI a. J.C. al Mediterráneo Occidental a través del mundo fenicio aunque asociada a una misma idea religiosa que los propios griegos llevaron al sur de Italia.

Es evidente el paralelismo existente entre ciertas piezas cerámicas de Cartago y de Chipre desde períodos orientalizantes y arcaicos (15), lo que viene a ratificar la estrecha vinculación existente entre Cartago y Chipre que propiciaría la llegada a occidente por rutas fenicias de modelos iconográficos bien chipriotas o bien reelaborados por griegos posiblemente en Chipre como parecen precisar las indicaciones antes aludidas.

(13) Karageorghis, V. (1974): "La ceramique chypriote de style figure. Age du Fer (1050-500 a. J.C.)». Colab. GAGNIERS, Roma, págs. 91-93.

(14) Karageorghis, J. (1977): Pág. 209.

(15) Cintas, P. (1970): "Manuel d’Archèologie Punique», I, Paris, pág. 360. 
Además, desde comienzos de la época clásica deberemos valorar la realidad genérica de un ambiente mediterráneo matizado por lo griego. La helenización del mundo cartaginés aportó al Mediterráneo Occidental la adopción de cultos griegos, hecho que también se produjo en Sicilia donde los púnicos se encontraban en estrecha vecindad con los griegos. "Las relaciones entre los púnicos de Sicilia y los de Cartago fueron tan estrechas y constantes que deben interpretarse como una de las huellas más lejanas de la antigua influencia de la Sicilia griega sobre Cartago (16)». Una de las consecuencias de estas relaciones se plasmará en la sustitución de las imágenes orientales de la diosa por estatuillas de tipo griego así como también por la adopción de los tipos de los grabados que ilustraban los cuños monetales sicilianos.

Además, Sicilia, que a un mismo tiempo era parte griega y parte púnica, testimonia la existencia en su suelo de un auténtico culto egipcio que es exponente de aquella realidad que expresamos al aludir a la iconografía de la diosa en cuanto a la toma de elementos egipcios en su tocado y tal vez también en su manifestación de figura alada.

En las relaciones entre Sicilia y Egipto se distinguen tres momentos esenciales (17), que quizás pudieran hacerse extensivos al resto del Mediterráneo Occidental. Tales etapas responden respectivamente a los períodos sicilianos arcaico (s. VII-VI a. J.C.), helenístico (s. III-I a. J.C.) e imperial romano s. I-III de J.C.).

El primero de ellos se caracteriza por ofrecer una facies homogénea de egiptización tanto en las zonas púnicas como en las griegas, que manifiestan cómo la isla participó de unas relaciones comunes con Egipto si bien debió existir un intermediario posiblemente representado por mercaderes griegos que actuasen paralelamente al movimiento comercial de fenicios y púnicos. Tras una etapa de la que no existe documentación en el sentido del material que nos ocupa, se produjo ya en el período helenístico, igual que parece ocurrir en Iberia y en particular en Elche, un resurgir de relaciones con lo egipcio o en general con una facies orientalizada y «eso corresponde al cambio producido en la realidad histórico-política del mismo Egipto, a su más íntimo contacto con la cultura griega, contacto que se manifestará fecundo también en el campo religioso con la creación del nuevo dios Serapis quien, junto a su diosa paredra Isis, ya cuenta en el mundo Occidental, aunque ahora, asumiendo una forma profundamente grequizante, se prepara a conquistar el interés y la devoción del oikoumene grecorromano (18)".

Pero mientras estas relaciones de matiz egipcio se producen en Sicilia, también allí se dan cultos vinculados al Asia Menor evidenciables por los testimonios existentes relativos a Cibeles y Atis (19), por lo que esta isla se nos muestra también como eslabón de unión entre aspectos religiosos aparentemente distintos y posible nudo donde se fundieran ideologías similares que dieran lugar al aspecto iconográ-

(16) Cintas, P. (1970): "Manuel d'Archèologie Punique», II, Paris, pág. 362.

(17) Sfameni, G. (1973): I culti orientali in Sicilia». Leidin, págs. 101 y 102.

(18) Sfameni, G. (1973): Pág. 103.

(19) En el santuario siracusano de Bitalemi fue hallada una representación de estilo jónico de la diosa con el león datable según Sfameni entre los años 550-540 a. J.C. 
fico de la diosa alada, si bien ha sido en Elche donde ha sido descubierta la pieza de este tipo que ofrece mayor antigüedad (20), hecho a valorar puesto que tanto las piezas de Cartago como las de Ibiza son de fecha posterior.

Los hallazgos del Parque de Elche confirman además las relaciones, contactos o participación en un mismo ambiente ideológico y cultural mediterráneo de Etruria e Iberia, pues la presencia de las estatuas-urna halladas así como la esfinge portadora del espíritu del difunto, que temática y técnicamente puede paralelizarse con el "Caballero Marino» de Vulci, dan sobrado testimonio de ello.

Iberos y etruscos participaron de una misma corriente cultural, tamizada por lo griego y posiblemente emanada del mundo sirio que a su vez ya había integrado en sus concepciones todo el sincretismo espiritual del Próximo Oriente, puesto que en Iberia, igual que en Etruria, incidieron tradiciones y creencias, ya entonces milenarias, procedentes del área sirio-fenicia, pero probablemente reelaboradas por los mundos fenicio, chipriota y griego, pues ya desde principios del siglo VII a. J.C. se consolidó plenamente en el extremo occidente mediterráneo el período hoy llamado "orientalizante" que fue el resultado de contactos crecientes con comerciantes fenicios imbuidos de un bagaje religioso y material asimilado de la zona siria y en buena parte filtrado por Grecia y sus centros itálicos. Ese impulso procedente de lo helénico, tal vez a través de la Italia meridional, marcó en Chiusi la tipología de las estatua-urna etruscas, "herederas de los canopos y que suponen un compromiso entre aquellos y la escultura el piedra" (20). Además en Chiusi, durante la época arcaica, gran parte de las representaciones humanas realizadas son femeninas y reproducen un modelo sirio ligado al culto de Ishtar y asimismo la esfinge, agregada en el Egeo a esta diosa y transportadora de almas, es frecuente en la estatuaria funeraria etrusca.

Existió pues en Etruria una creencia en la diosa de los muertos, lo que implica también allí, igual que en Iberia, un culto a la Gran Diosa, cuyo sincretismo afectó a toda la cuenca del Mediterráneo. Realidad lógica en lo que respecta a nuestra Península puesto que había tenido contactos con Oriente desde el III milenio a. J.C., evidenciados por la tipología de los ídolos eneolíticos (21), y consecuentemente también en Occidente, en Iberia, estaba sembrada la semilla, desde hacía mucho tiempo, del culto de la que en estos momentos a que aludimos será aquella Gran Diosa.

Surgieron en consecuencia artes plásticas vinculadas a creencias religiosas que configuraron el sincretismo de sus divinidades emanado de esas relaciones y contactos con un legado material y espiritual de raíz oriental.

Las relaciones generales intentamos hoy comprenderlas atendiendo a unos influjos orientalizantes originarios de Mesopotamia y adoptados en la Alta Siria, una aportación griega asimiladora de connotaciones egipcias llegadas a través de las es-

(20) Hus, A. (1976): "Les siècles d'or de l'histoire etrusque (675-475 a. J.C.)». Latomus, 146, págs. 118 y 181 .

(21) Ramos, R. (1982): “Arqueología prehistórica de la península Ibérica». Ed. Picher. Elche, págs. 207 y 208. 
tancias de jonios en aquel país y de la adaptación consecuente de tipos e iconografía, una tamización de ideologías y unas comunicaciones entre pueblos que, una vez captados los influjos citados, los mantienen y disuelven en el área del Mediterráneo Occidental cuyos pilares estaban constituidos por la zona Suritálica, Sicilia, Etruria, Iberia y Cartago. Por lo que en una fase previa a las relaciones directas entre aquellas debió producirse la aportación orientalizante asimiladora que matizó el ambiente mediterráneo de la época. Se trató pues de estímulos orientales difundidos y aceptados en el Mediterráneo Occidental con inmediata anterioridad a la consolidación de los mundos occidentales: Un espíritu común que alimentó a aquellas diferentes culturas y que más tarde, ya personalizadas tales culturas «nuevas", dio lugar a unas consecuentes relaciones entre ellas.

Es muy probable que el primer período propiamente ibérico comenzara a manifestarse a mediados del siglo VI a. J.C. alimentado por corrientes fenicias y chipriotas asociadas con elementos anatolios y egipcios amalgamados con otros griegos del Asia Menor, de las colonias griegas itálicas, de Etruria y de Cartago.

Si en el área íbera son frecuentes los productos exóticos y reflejan los contactos aludidos con otras culturas, no menos significativa es la presencia de cerámica ibérica de sus tres períodos, Arcaico, Clásico y Helenístico (22), en todo el occidente mediterráneo, lo que equivale a expresar la realidad de ese ambiente prerromano citado a través de etapas concretas durante las cuales se produjo un intercambio evidente de objetos de ideas entre Iberia, Sicilia y el área Suritálica, Etruria y Cartago, por lo que se manifiesta que estos mundos surgieron, vivieron y evolucionaron durante unos mismos momentos, y a ello habrá que sumar la presencia de mercenarios íberos en Grecia, Sicilia y Cartago que debieron importar estímulos importantes, por lo que todos los pueblos del área occidental citada participaron posiblemente de una misma idea religiosa que en Iberia y en el mundo púnico se plasmó esencialmente a través de las imágenes del toro y la diosa alada. 